\title{
Increase of Efficiency of Use of Innovative Capacity of the Region
}

\author{
Marina T. Tekuyeva \\ Murat A. Volov \\ Amina R. Volova \\ Rita H. Kushbokova \\ Kabardino-Balkarian state university of H.M.Berbekova Russia, Kabardino-Balkar Republic, Nalchik \\ Email: tekueva.m@mail.ru
}

Doi:10.5901/mjss.2015.v6n2p44

\section{Abstract}

Economic development of Russia puts in the foreground the actual need of reorganization in structure in combination with expansion and high-quality change of the results of effective production's growth, and also formation of market infrastructure. The most essential transformations in market structures concern, first of all, formation of the Russian market of innovations, dynamic development of the market of the risk capital, especially in branches of "high technology", and also developments of technical base for the financial markets. An integral part of the management of innovation infrastructure of the region - the mechanism of monitoring and evaluation of its condition, and, more importantly, the effectiveness of the operation. In the article the analysis of existing methodologies for the assessment of the innovation infrastructure, which revealed the ambiguity of some questions. Because at the moment there is no universal and adaptive methodology of an assessment of a state and efficiency of innovative infrastructure of the region, authors developed a technique of an assessment of development of innovative infrastructure of the region which allows not only to investigate in a complex the level of its development, but also to apply to the majority of regions of Russia.

Keywords: innovations, innovative development, innovative potential, investment activity of the region

\section{Introduction}

According to normative approach the assessment of a level of development of innovative processes in regional economic systems has to be based on studying of necessary and sufficient imperatives of innovative development. Exarticulation of the imperatives determining innovative potential assumes:

- installation of level of compliance of each factor of regional economic system to requirements of innovative development;

- detection of the general regularities of course of innovative processes;

- assessment of level of adaptation of separate elements of regional economic system to these processes;

- the offer of systems, effective for this territory and measures providing transition of factors of innovative development to the demanded state (Tekueva, Volov 2013).

For the systematized analysis and the solution of problems of ensuring proportional development of regional economic systems it is necessary to formulate the determinants defining differences in course of processes of innovative development in the territory of the region, to reflect fully specifics of conditions and factors of formation of the innovative environment in strategy of innovative development of the concrete territory.

Categories of favorable climate which are necessary for development of innovative processes of strategic planning of regional development are concentrated in the following two groups of factors (Tekueva, Volov 2013):

- institutional factors (including a normative and legislative basis) which provide effective use of "the saved-up intelligence", existence of investment resources of risk character (venture type);

- development of innovative infrastructure which provides interaction both with the supporting branches supplying economic entities with necessary resources (accessories, information, banking, insurance and other services), and interaction with local community (authorities, public organizations, etc.). 


\section{Research Methodology}

Possibilities of an exit of the Russian economy from the world financial crisis which affected her and transition to innovative model of development demanded activation of investment process, for a power impulse for a post-crisis trajectory.

Sharp decrease in science and equipment and investments within the last decade led to big lag of Russia from many developed countries of the world in quality of life and economic efficiency. Ensuring structural reforms and expanded reproduction on a modern technological basis, blocking of devaluation of capital funds- demands creation of complete model of management of investment processes, both over all country, and in each region (Expert, 2013).

The main aim of regional scientific and technical policy is the rational combination of the purposes, scientific and technical and social and economic development. In this regard, sciences and technologies, the policy has to be more focused on satisfaction of needs of inhabitants of the region, improvement of quality of their life, it is closely connected with the solution of social and economic problems of the population.

Innovative investment potential of the region needs to be considered as the open, dynamic, probabilistic social and economic subsystem of the region capable to self-updating, adaptation to changes and generation of scientific and technical progress.

The dynamic and uncertain environment, subjected to fast high-quality changes, puts forward new problems of management of innovative development which can't be solved on the basis of traditional management or direct loan of foreign experience. Transition to innovative development demands not only optimization of resources and mobilization of potential of an innovation, but also demands system transformation of institutional structure of economy (Galachiyeva, Kuyantsev, Kuyantsev 2010). An innovative development of the region, having synergetic effect, and particularly, introductions of an innovation to the industries will lead to introduction of innovations to many other sectors of economy, and as a result creates a phase of restoration of a business cycle in the whole economic system. Therefore, active introduction of innovations can give incentive to overcome global financial crisis.

As an important component of development of the region in the field of an innovation it is necessary to examine internal motivation of its economic entities to innovative activity. Development of innovative processes is promoted by initiation of innovative activity of subjects of managing, formation of their recognition of innovative transformations (Miloserdov, 2006). Formation of innovative activity due to internal motivation of subjects of the economic relations acts as the main prerequisite of innovative formation of regional economic system as development has to be carried out by efforts of people, and not just in their interests.

The main objective of stimulation of innovative processes in the region within imperatives of development is creation of the conditions formed according to the level of a susceptibility of regional economic system to innovations and defining efficiency, regularities and possible prospects of its further development. In a general view the process of formation of these conditions can be consider as a creation of opportunities for manifestation and the fullest implementation of the functions.

Sufficient imperative of innovative development is realization of the mechanism of transformation of innovative resource capacity of the region into ability to provide reproduction of innovations in the scales providing sustainable social and economic development of the territory. In this regard in policy of innovative development of regional economic systems the important problem is solved by stimulation of a susceptibility of the territory to innovations, both state, and regional bodies of authority and management.

At the present stage in the conditions of world financial crisis there is actual a development of innovative approach to adaptation of economic entities to all-system not stable (Expert 2013), ( Santo 1990), (Glasheva, Imamova and Tekueva, 2014).

In Russia the considerable fund of innovative offers, development and business projects almost in all branches of a production activity is already put. There is also an experience of localization of separate innovations, but only in the extracting branches. In principle the excess profit which turns out from sale of some production of innovative productions, owing to its absolute competitive advantage expands its output, also allows and to receive means for work of other types of production.

To increase demand in region economy for high-tech innovations, the importance of innovative infrastructure the organizational and economic mechanisms of new type created for overcoming of barriers to innovations can. We suggest to realize such new form of support, motivation and self-organization of scientific community and a transfer of new technologies in the form of the innovative and technological centers.

Introduction of research works demands the general database for professionals and experimental technologies, the register of innovations, to the innovation-active and innovative and susceptible enterprises. Existence of management on 
leasing is dictated by complexity of process of introduction of new technologies and need of effective operation of commercialized innovations.

Designed investments in the region, are characterized by a constancy and a stepwise process of investments into fixed capital stock, introduction of innovations of technical, technological and etc, a community of total investments of regional economic entities and infrastructure objects (Tekueva, Volov 2013).

The purpose of this investment project is concentrated on timely acceptance of the regulating measures for rationalization of interaction of elements of investment process and achievement of necessary efficiency of using the means of investment.

The main targets of increase in volumes of innovative investment in the region for its authorities of perspective and strategic social and economic development, according to authors, are:

1) allocation of priority researches and well designed projects, basic researches, their financing, budgetary and joint with other investors;

2) definition of the marketing mechanism of realization of innovations, their animations and diffusion;

3) establishment and introduction into practice of scientific and innovative activity of methods of the differentiated financing of innovative projects within separate economic entities, production and social infrastructures based on various combination of volumes of the budgetary (own) funds and also attracted and loan financial resources. Thus we find it possible to present direct and innovative investment of fixed capital stock in the region (scheme 1).

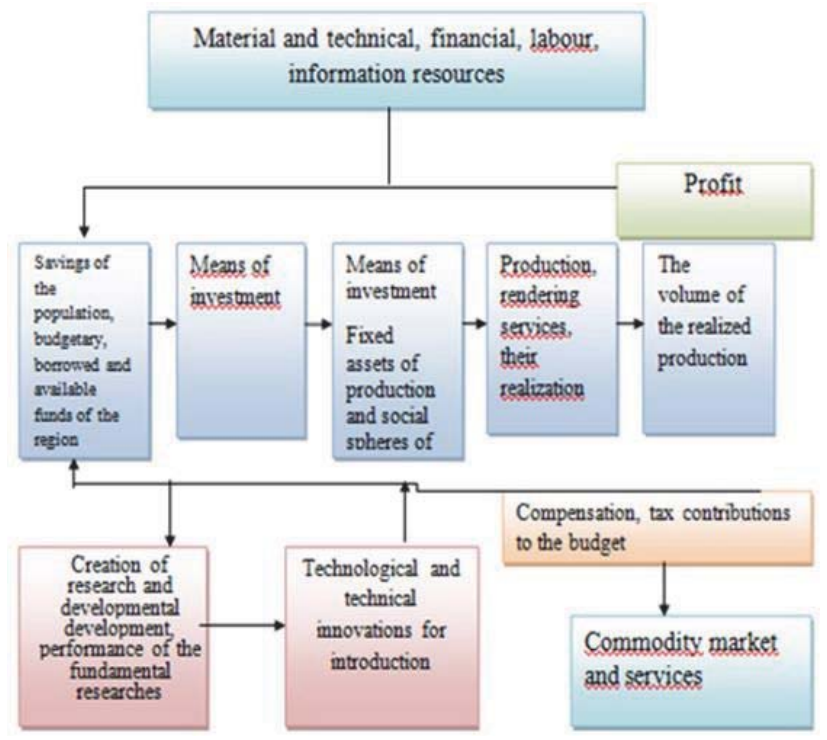

Scheme 1. System of interaction of the formed means of investment, their direction in fixed capital stock and creation of innovations

\section{The Main Part of Research}

The important place in studying of a problem of increase of innovative investment potential is taken by research of its regional features that will allow to estimate the developed shifts from a position of their further development. In the republic the separate growth of economy is observed. It follows from the following signs: for example, in 2010 in KBR GNP, industrial production - 112,5\%, production of agriculture - 111,6\%, the volume of contract works - 109,3\%, commissioning of houses $-105,2 \%$, a turnover of retail trade $-118,1 \%$, a turnover of public catering $-122,9 \%$, the monetary income per head $-116,5 \%$ tended to growth (Tekueva, Volov, 2013).

For the analyzed years of GNP raised generally due to production of services (in $2010-105,7 \%$ ) whereas the corresponding characteristics of production of goods grew with much lower rates (in 2011 - 102\%). As a result of this process the structure of GNP changed with a prevalence of specific weight of a services industry.

In recent years the investment sector remains at one of so-called, "painful points" of regional economy. Because of limited economic resources of society, composed investment policy, concern all levels of management. In recent years 
there was a sharp decrease in capital investment, thus the greatest recession is experienced by production investments that causes delay of rates of updating of the main reserves (Tekueva, Volov, 2013), (Glasheva, Imamova, and Tekueva 2014).

The main goal of regional investment policy of the republic is in guaranteeing economic growth, attracting investments into effective and competitive production, creation of competitive sectors in priority economic activity.

Investment activity in the republic is not very good in comparison with more developed regions of the Russian Federation. During financial crisis an important point is the question of sources of development of the region, besides federal.

In a total amount of investments into fixed capital stock prevail borrowed funds though the volumes of investment are rather small, it is the fact of low-development of credit and financial system of the republic, the share of own means of the enterprises in the total amount of investments into fixed capital stock is also insignificant, because of a high share of the unprofitable enterprises. In the Russian Federation is observed the dynamic growth of the volume of investment into fixed capital stock.

Investments into fixed capital per head in KBR are 4 times less than in other regions of the Russian Federation. Than 20\% of capital investments whereas in 1995 was - 35\%, in agriculture in 2012 of $11 \%$ of the level of 1995 (table 1).

Table 1 - Investments into fixed capital on branches of economy of KBR *, \%

\begin{tabular}{|l|c|c|c|c|c|c|c|c|c|c|c|}
\hline Indicators & 1995 & 2003 & 2004 & 2005 & 2006 & 2007 & 2008 & 2009 & 2010 & 2011 & 2012 \\
\hline Investments in OK - all & 100 & 100 & 100 & 100 & 100 & 100 & 100 & 100 & 100 & 100 & 100 \\
\hline Industrial activity & 35 & 40 & 23 & 33 & 78 & 23 & 27 & 33 & 23 & 30,3 & 35,8 \\
\hline agriculture & 31 & 20 & 8 & 3 & 2 & 4 & 4 & 5 & 3 & 1,9 & 4,1 \\
\hline Construction & 3 & 4 & 6 & 2 & 2 & - & - & 1 & 2 & 4,0 & 8,0 \\
\hline transport and communication & 4 & 4 & 13 & 18 & 8 & 29 & 20 & 15 & 16 & 24,4 & 12,2 \\
\hline trade and public catering & 18 & 5 & 3 & - & 3 & - & - & 1 & 3 & 1,6 & 2,1 \\
\hline housing construction & 12 & 18 & 35 & 18 & 3 & 9 & 5 & 5 & 6 & 6,1 & 4,9 \\
\hline Public administration & & & & & & & & 1,6 & 6,3 & 13,5 & 13,3 \\
\hline The other & - & 13 & 18 & 33 & 9 & 38 & 45 & 42,3 & 43 & 18,3 & 20,6 \\
\hline
\end{tabular}

* It is calculated on a statistical year-book: Kabardino-Balkaria in figures, 1995 - 2012.

Efficiency of capital investments depends on rate of technological progress of the country and economic efficiency of production. The problem is that rather smaller investments have to provide big production of increase of production of goods (Tekueva 2013).

KBR occupied the 68th place in an integrated rating of investment potential of Russia, and treated regions with an insignificant potential and medium risk. The assessment of investment climate of the republic potential investors is carried out on the basis of a large number of negative information on regions of the North Caucasus that leads to distortion of true situation and understating of level of appeal.

The main conditions which promote inflow of investment resources to economy of Kabardino-Balkar Republic, have to be:

- creation of attractive legislative bases for increase of investment activity and reliable protection of the made investments;

- increase of investment appeal of the enterprises and branches;

- increase in financial base of investments due to broad use of investment goods and involvement to them of strategic investors;

- bilateral agreements with foreign investors about mutual encouragement and assistance to investments.

To attract foreign investments, there will be created works on preparation of specific projects according to the international standards.

Requirement to develop state programs of structural modernization of priority hi-tech sectors of mechanical engineering for certain groups of companies. It can be financed from the budget of the objects having its intended purpose noncommercial character, and also basic scientific researchers can be financed from the budget. Other types of the centralized investments can be carried out only on a returnable, paid and competitive basis (Tekueva 2014).

Reasonable use of elements of national wealth which are granted by the nature or are created as a result of socially useful work, is one of expedient ways of methods of economy of the republic of a depression. In KBR, unlike many other regions, there are unique recreational resources which have to be turned into a real source of economic 
growth of the republic. In the organization of recreational activity the central place will be taken by resources of mineral waters for the organization of resort and medical activity and mountaineering. Development of this branch including their reshaping, would play a positive role in increase of employment of the population, reduction of unemployment in the republic. This situation is very attractive as KBR is the labour-abundant region. The unemployed population would take part, besides the sphere of tourism and a recreation, as well in infrastructure branch of tourism. Economic management of the resort and tourist complex in KBR has to provide:

1) maintenance of stable market capacity of sanatorium services;

2) creation and reproduction of conditions of steady current activity of resort tourism organizations and resorts, sustainable development of resorts and tourist complexes;

In the republic there are such favorable conditions for development of agricultural production which can provide a resort and recreational complex with its own food base; the enterprises of the industry - to carry out orders of a resort and recreational complex on production of medical equipment and necessary technology. The structural regional policy has to be based on efficiency of branches and concrete enterprises.

Scales of innovative activity within a year increased practically in all branches. Leaders who define an overall picture innovative activity:

1) telecommunications agency and telecommunication services;

2) enterprises of an industrial complex of the republic (tab.3).

Table 3 - Innovative activity of the organizations of various branches of KBR *

\begin{tabular}{|l|c|c|c|}
\hline \multirow{2}{*}{} & \multicolumn{2}{|c|}{ Share of the organizations which are carrying out innovative actions ( \%) } \\
\cline { 2 - 4 } & 2010 & 2011 & 2012 \\
\hline In general: on selection & 27 & 34 & 39 \\
\hline transport and communication & 39 & 37 & 53 \\
\hline Industrial activity & 36 & 48 & 50 \\
\hline Construction & 24 & 34 & 16 \\
\hline trade and public catering & 16 & 28 & 32 \\
\hline agriculture & 21 & 28 & \\
\hline
\end{tabular}

* the Table is made according to the examination, and according to calculations of the author

At the regional level the urgent task consclude in creating and developing a wide network of the enterprises, the institutions and the organizations which are directly participating in innovative process or serving this process - filling free niches of the innovative market. Under the current legislation the government of area the right to create such enterprises which are in introduction of local authorities, and also to promote formation of other objects of infrastructure of the innovative market arising at the initiative of various enterprise structures.

However, it is necessary to emphasize that the problem of formation of innovations of infrastructure of the market for each area can't be unambiguously solved by only one scheme. Always there is a differentiated cost - the based approach which considers interests of the region, its innovative characteristics and the existing scientific and technical basis (Tekueva 2014). On our representation, it is preferable to provide full independence of each regional education in a choice and formation of regional structure of the innovative market, in achievement of optimum balance of supply and demand of innovations in this market.

In implementation of a choice of a configuration of regional infrastructure of the market of innovations modeling of innovative capacity of the region can play a significant role. In our representation, the model of innovative potential has to structure the elements of innovative infrastructure, most typical for this region, to basic massifs from which it is necessary to distinguish the following:

1) the massif of the scientific and technical organizations which are available in the region, such as research institutes, research laboratories, chairs of higher education institutions, societies of scientists and inventors, etc.;

2) the massif of the design and experimental organizations of the region which join in the institutes of technology which are engaged in developmental and project works, test stations and grounds, etc.:

3) the massif of the corporate organizations of diversified character, the covering wide range of different types of innovative activity and providing scientific and technical cooperation in the sphere of innovations;

4) the massif of manufacturing enterprises and organizations which have capacities for execution of innovative 
activity and which can act as both producers and consumers of innovative production;

5) the massif of the enterprises and organizations which carry out service of innovative process, including transport, repair, assembly, etc.;

6) the massif of firms which provide various intellectual services, including examination, consulting, engineering, etc.;

7) massif of information support of innovative activity, such as telecommunications agencies, mass media, computer centers, advertizing agencies, etc.;

8) the massif of staffing, training, professional development as a part of which higher educational institutions, technical training colleges, etc. are important;

9) the massif of the organizations which are capable to provide the economic mechanism of functioning of the market of innovations, a legal regulation of actions of participants of innovative production, financial and resource and administrative and organizational support of innovative business. This massif joins banks, financial, legal, administrative, tax, customs services of the region, regional investment and innovative funds, leasing and venture firms, etc.

Developments of innovative strategy of the region is consolidation and strengthening of power of innovative potential in the region (Tekueva 2014). In this ratio there is a need for development and realization of a uniform complex of the actions directed on consolidation of experience of shots, material and financial resources of all branches and organizations, and also other enterprise structures which function on the territory of this region.

In this process local public authorities which can provide necessary coordination of innovative activity in scales of this region have to play a special role. Such approach to a solution, in principle, is justified. Regional potential has to be considered and develop as the multilink and integrated uniform system including not only the corresponding potentials which are under authority of regional authority, but also the total scientific and technical potential which is available for all other economic entities located in the territory of this region, irrespective of branch accessory and forms of ownership has to be considered.

One of the most important conditions is realization of strategy of development of innovative capacity of the region adaptation of the enterprises and administrative structures to conditions of innovative type of development. Here we speak about ability flexibly to adapt to changes of external (internal) conditions, in due time to find and consider the arising shifts, to embody progressive tendencies in the course of development and deployment of the current and strategic innovations.

Because of influence of some internal and external factors of state of the economy and mercantile orientation to receiving speculative profit, a significant amount of economic entities in regions are still poorly aimed at systematic updating of production, achievement of scientific and technical leadership and providing the highest level of competitiveness. On practice we can see that the reforms which are carried out in Russia on change of organizational and legal forms of the enterprises, improvement of tax and budgetary policy in itself can't automatically provide transition to innovative type of managing.

The most important, in our representation, radical reorganization, first of all, is organizational structure of each branch. The most acceptable thing about this question, it is represented that economic entities of the region developed special target programs for adaptation of organizational structure and the personnel of the enterprises in which the system of requirements and the measures adequate to requirements of innovative type of managing, and also use of market levers and incentives has to be provided. In these unique business processes of innovative adaptation actions for creation of essentially new divisions and services have to be developed to execute the following functions:

1) strategic management, forecasting and programming;

2) quality management of a product and competitiveness;

3) management of innovations;

4) marketing, advertizing and commercial activity;

5) development of a network of service consumers;

6) information, information support, etc.

Now process of innovative development of Russia is at the initial stage. The share of the Russian industrial enterprises which are really carrying out development and deployment of new technologies by 2008 hardly reached $10 \%$. In spite of the fact that approximately in 30 Russian regions declared intention to develop innovative sector, only 5-6 regions among them, according to experts of Higher School of Economics, are ready to transition to an innovative way of development. And if abroad the exit from an economic crisis is associated with search and introduction of competitive technologies, in Russia at many key enterprises, including state enterprises, while determining anti-recessionary priorities first of all is carried out rejection of financing of expenses on modernization, research and development and innovations. 
From the analysis of a condition of innovative infrastructure of the Russian regions it is necessary to draw a conclusion that there are serious divergences in creation and development of its objects. As especially important task in nearest future it is possible to consider creation of such infrastructure of innovative activity which allows to provide necessary balance of resources of development of the innovative enterprises of the region.

Therefore at permission of a question concerning a choice of optimum innovative infrastructure it is offered to allocate the following components of an assessment of innovative infrastructure of the region (scheme 2).

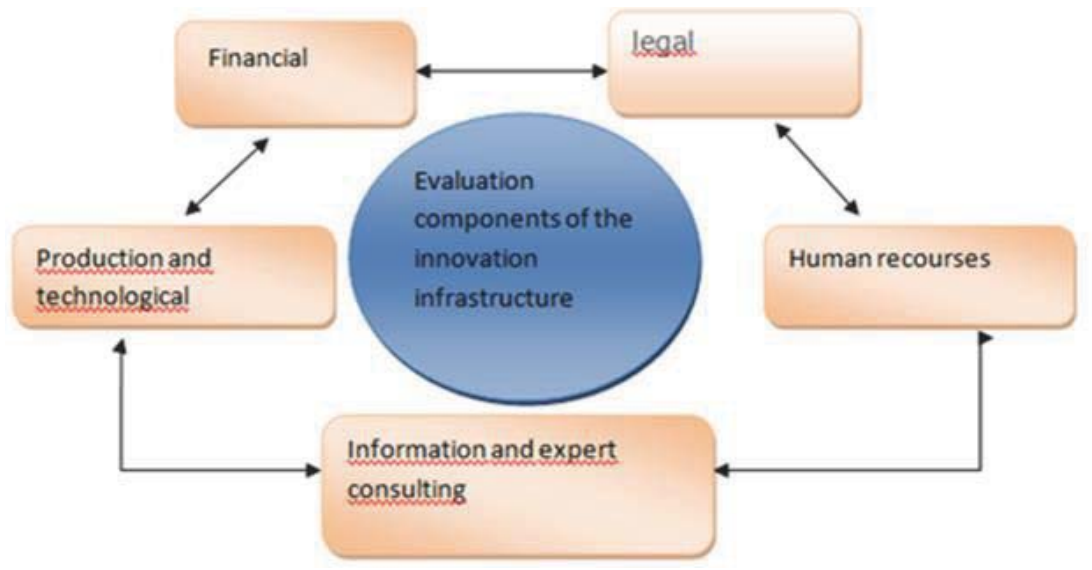

Scheme 2. Components of an assessment of innovative infrastructure of the region

The relations between components of an assessment are established at creation of models of functioning and management of innovative infrastructure of the region. For the last the periods, economists spend all their time on a solution of the problem of creation of optimum model of innovative infrastructure.

Further investigations of innovative infrastructure of the region need the analysis and an assessment of each its component. Given vent has to consider all characteristic features of implementation of innovations and helpfulness of the use of the available resources.

Integral part of a control system of innovative infrastructure of the region - the mechanism of control and an assessment of its state, and that is even more important, productivity of functioning. The analysis of the existing methodologies of an assessment of innovative infrastructure showed us that, despite their variety, exists an ambiguity in the following questions:

- what is the role of a level of development of innovative infrastructure in providing a sustainable development of the region;

- how it will be classified, systematized and estimated a component of innovative infrastructure of the region;

- what indicators are responsible for the characteristic of a state and productivity of functioning of innovative infrastructure of the region, and also, whether there is a possibility of receiving really applicable complex indicator, etc.

Practically all discussed techniques are applicable in certain special cases, for the set region parameters. On our representation, the universal and adaptive methodology of an assessment of a state and efficiency of innovative infrastructure of the region is absent at the moment.

Then there was developed the technique of an assessment of development of innovative infrastructure of the region which allows not only to investigate in a complex the level of its development, but also to apply to the majority of regions of Russia. We will show the main maintenance of a technique in the form of algorithm of actions (scheme 3 ). 


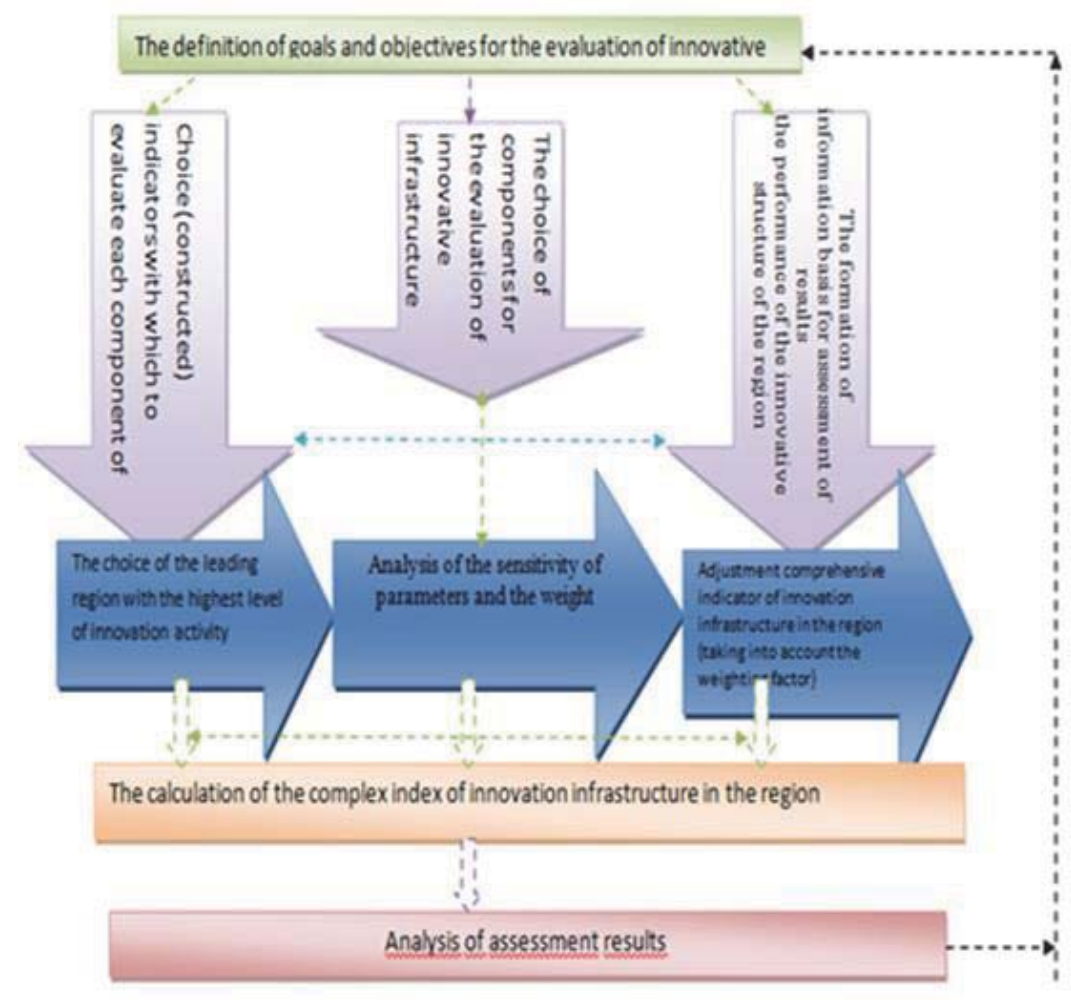

Scheme 3. Algorithm of an assessment of development of components of innovative infrastructure of the region

The algorithm of an assessment of development of components of innovative infrastructure of the region is applied to finding of the priority direction of development of innovative infrastructure of the region.

Thus, it is possible to analyze simply influence of various factors on a level of development of innovative infrastructure of the region.

It is possible to make the following conclusion of the received results of an assessment of innovative infrastructure of Kabardino-Balkaria Republic:

1. In regional economic system of managing there is no steady large-scale business relations between the state, science and business that leads to insufficient science financing by business and consequently, and to incomplete use of innovative infrastructure.

2. The existing indicators show potential ability of the region to more intensive innovative development, but the created regional innovative infrastructure hasn't create yet for this purpose necessary prerequisites.

3. To strengthen innovative infrastructure of the region it is necessary to intensify use of resource opportunities of its development (for a start, strengthening of a financial component which defines development of all other components).

From the analysis of development of innovative infrastructure of the Russian regions we can see existence in the region of business incubators of an innovative profile, the innovative centers and science and technology parks has a great influence on its level. Their successful work involves building of indicators which characterize a financial component of an assessment of innovative capacity of the region.

The approaches offered in dissertation research in improvement of methodology of an assessment of a level of innovative infrastructure's development of the region allow developing the whole system of concrete techniques of an assessment of a contribution of each of resource components to accumulation of innovative capacity of the region. Use of such techniques can make more reasonable decisions of the regional authorities on allocation of economic resources on creation and development of objects of innovative infrastructure.

In development of the regional innovative system (RIS) programs of innovative and investment development of the region have to play an essential role. As an example, it is possible to use mechanisms of regional development of EU countries which are in decentralization of state planning of development RIS. It is expedient to make long-term programs of development in the form of contracts which guarantee an involvement, interest and responsibility for implementation of 
the obligations of all participants of process of programming, all levels of the power as it is defined in contracts. The simplified model of organizational and institutional structure RIS looks like that: (scheme 4)

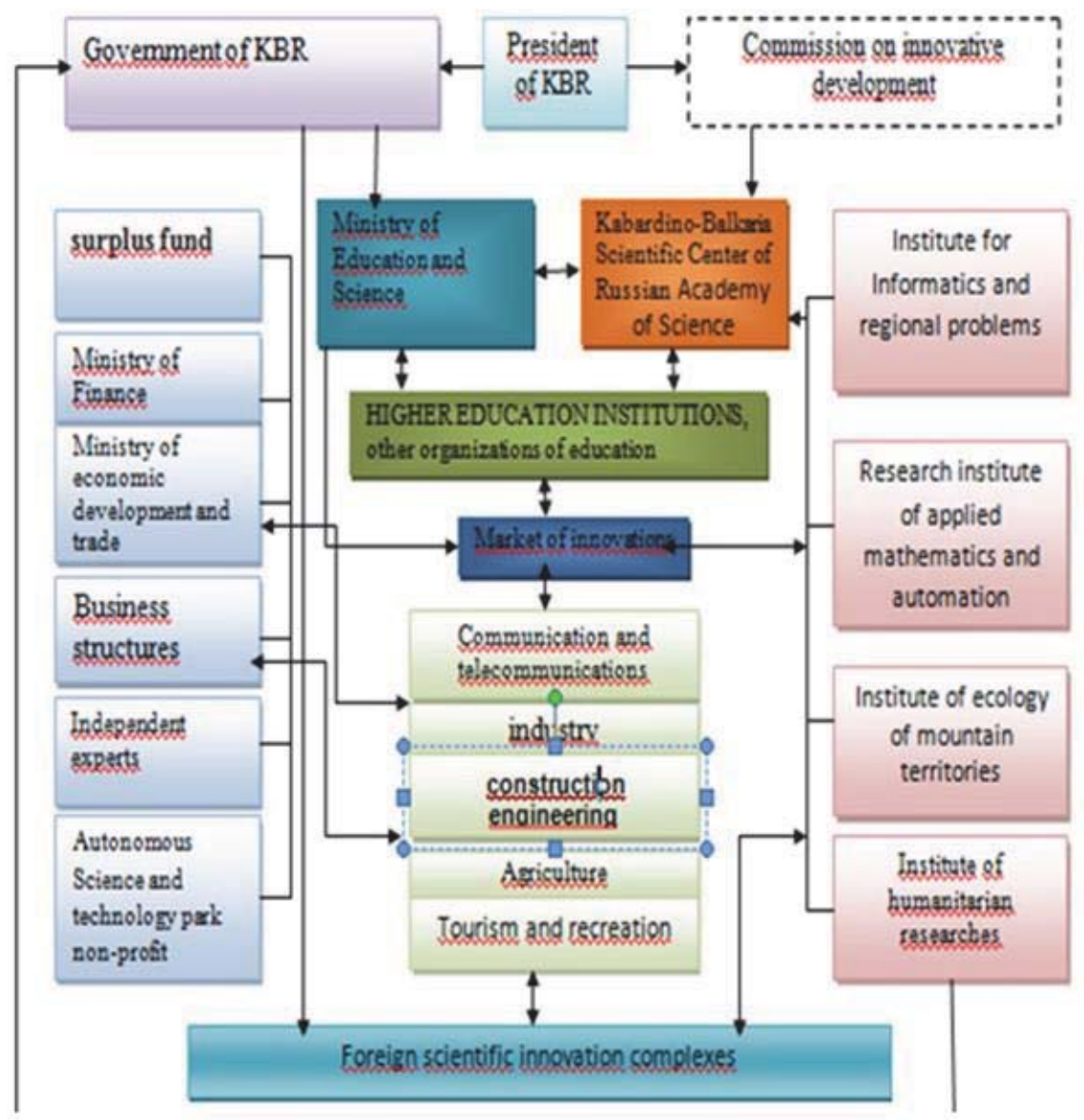

Scheme 4. Model of organizational and institutional structure KBR RIC

\section{Conculsions}

In conclusion we can say that the role of the state in development effective the KBR RIS is considerable and covers all stages of innovative process, but, despite it, it is necessary to remember that attempts of an excess regulation of innovative activity from the government quite often lead to an inefficiency of the programs organized together with business, as a result we see that the interest of branches of economy in implementation of innovative activity falls. It is correct to use at the same time various channels of support of innovative activity. Such approach reduces risks of "failures of the state" because of inefficient activity of concrete branches and in future it allows increasing the support of more effective ones. In the conditions of regions' economy the removal of existing innovation institutions, as with all the possible failure of their activities they perform certain functions and their minor disruption can negatively affect the innovation process. The best action is gradual replacement of incorporation (or embedding) of old institutions to the new system of support of innovative activity.

From the point of view of modernization of regional economy, against all-economic, social, legislative problems, it is necessary to search the new ways based on formation of effective innovative and investment strategy of development of the region.

\section{References}

Galachiyeva S.V., Kuyantsev A.I., Kuyantsev I.A. (2010). Methodological approaches to formation of strategy of management of innovative activity of the managing structures of regional economy the Russian Academy of Sciences of News of KBNTs Russian 
Academy of Sciences. 3(35)

Galachiyeva S.V., Akhmatova L.S., Hatsukov A.M. (2010). Formation and realization of investment strategy of the macroregion in the context of the theory of a sustainable development Scientific and technical sheets SPbSTU (Economic sciences) 6 (112)

Miloserdov V. V. (2006) The scenario of economic growth of Russia//Economy agricultural and processing the enterprises. 5. Pp 7-10.

Santo B. (1990)Innovation as means of economic development. - M.: Progress, 1990.-Pp 350

Tekueva, M, T (2011)System approach to research of problems of a sustainable development of rural territories of mountain regions//Terra Economicus. No. 9, 4-3. - Pp 204-207. Date Views 01.12.2014 www.elibrary.ru/item.asp? id=17339335.

Tekueva, M.T., (2013). Directions of development of innovative potential in the Russian Federation. "CIS: history, present, prospects", Scope academic house, UK, S Yorkshire, Sheffield (issue 12-4), pp: 78-82.

Tekueva, M.T., (2013). Problems of sustainable development of mountain areas on the example of Kabardino-Balkaria. "The journal "International journal of applied and fundamental research", 1. Date Views of 15/12/2014 www.science-sd.com/455-24274.

Tekueva, M, T, Volov M, A, (2013) Strategy of development of innovative capacity of the region (on materials KabardinoBalkarian)//Economy and business. 12-4. - Pp 202-205.

Glasheva, A.M., Imamova Z, Z, and Tekueva M. T, (2014). Innovations in economic education: essence and prospects of development. IV international scientific and practical conference "Innovations and Modern Technologies in an Education System", (issue 10), Vedecko vydavatelske centrum Sociosfera-CZ s.r.0., pp: 22-26. Date Views of 01.12.2014 www.sociosphera.com/conference/ 2014/innovacii_i_sovremennye_tehnologii_v_sisteme_obrazovaniya

Expert [An electronic resource] Date of the address: 15.12.2013 www.archive.expert.ru/internet/00/00-3475/vid.htm 